\title{
An Exploratory Study of Consumer Attitudes toward Green Cosmetics in the UK Market
}

\author{
Yifeng Lin ${ }^{1,2}$, Shaohua Yang ${ }^{3, *(\mathbb{D}}$, Haniruzila Hanifah ${ }^{3}\left(\mathbb{D}\right.$ and Qaisar Iqbal ${ }^{4}$ (i) \\ 1 Business School, Newcastle University, Newcastle upon Tyne NE1 7RU, UK; Lyfdaphne@163.com \\ 2 School of Innovation and Entrepreneurship, Yango University, Fuzhou 350015, China \\ 3 Graduate School of Business, Universiti Sains Malaysia, Penang 11800, Malaysia; Haniruzila@usm.my \\ 4 School of Management, Universiti Sains Malaysia, Penang 11800, Malaysia; qaisariqbal@student.usm.my \\ * Correspondence: shaohuayang@student.usm.my; Tel.: +60-199-488-143
}

Received: 11 September 2018; Accepted: 16 November 2018; Published: 19 November 2018

check for updates

\begin{abstract}
People's health awareness has extended from the food industry to the personal beauty industry. Consumers have increased their interest in natural ingredients, sustainable packaging, and other green elements of cosmetics. This research explores consumer attitudes toward green cosmetics. Data were collected through qualitative research instruments (focus groups) since the research aimed to discover in-depth consumer attitudes and feelings. There were 30 British females who agreed to be respondents in five focus groups. They were divided into five focus groups. The key findings of this research were the prevailing neutral attitudes toward green cosmetics due to the lack of knowledge and confusing market standards. The majority of respondents viewed price and performance as the most important factors when choosing cosmetics instead of green elements. However, given the growing awareness of natural and organic ingredients and green production, most respondents admitted the potential change of present neutral attitudes to be more supportive in the future. Green cosmetics is a new trend in the personal beauty industry. This study ascertains the consumer attitudes toward green cosmetics and calls for clearer green standards and regulations in the industry as well as advanced biotechnology to extract natural ingredients.
\end{abstract}

Keywords: consumer attitudes; green cosmetics; affective cognitive components

\section{Introduction}

According to Organicmonitor (2010) and Packaging Digest (2010), cosmetic firms regard green formulations, resource efficiency, and life-cycle assessments of their products as primary concerns when drafting sustainability blueprints. The cosmetics summits that centre on sustainable issues have drawn cosmetic consumers' attention to factors such as natural ingredients and environmental packaging, as well as ethical issues. Despite the economic challenges, the Natural and Organic Show held by Diversified UK attracted 600 exhibitors and 7352 attendees (Yeomans 2012). The positive feedback increased industry professionals' confidence in the growth of the green cosmetics market. The UK's cosmetic and beauty industry is increasingly affected by the food market because people extend their awareness from what they eat to what they put on their skin to ensure a healthy lifestyle. Mintel (2009) indicated that just over four out of ten (41\%) British females frequently check the label on the packaging about ingredients of the cosmetics they use. The common concern concentrates on potential risks of harmful chemicals to human health and the possibility of skin irritation. Powerful chemicals might pollute the environment. Influenced by the health trend, a growing number of consumers demand healthier cosmetics that will be gentle on the skin and minimise the harm to the environment. Empirical evidence suggests that more consumers in Europe are becoming more environmentally responsible in terms of their habits and lifestyles (Stone et al. 1995). Minte's (2018) investigation showed that 
$50 \%$ of British consumers favour cosmetics made from natural ingredients. This figure is the highest in Europe.

Motivated by favourable demand, hundreds and thousands of companies and suppliers are now producing and selling cosmetic products which they claim are 'green' and better for the user and the environment (Green Choices 2012). Mintel (2010) suggests that a constant innovation campaign about natural and organic ingredients will help maintain growth in the UK's beauty products industry that is worth $£ 6.7$ billion.

However, there are obstacles that could destabilise consumer confidence, including the lack of regulation and misleading marketing information (Mintel 2010). Different standards and abundant cosmetics boasting green concepts confuse enthusiastic consumers. Consumers are confused by the different standards and exaggerated marketing of green cosmetics. They find it difficult to select green cosmetic products. Mason (2012) found that cosmetic consumers purchase benefits, not features. Therefore, they pay more attention to functions rather than detailed ingredients. In addition, a study indicates that the UK Society of Cosmetic Chemists in 2008, when focusing on the natural versus synthetic debate (Bird 2009), was concerned that the media was spreading the message that the natural ingredients were inherently safer.

Consequently; cosmetic chemists fought hard against the idea that natural ingredients are inherently safer than their synthetic counterparts. Ingredients should be chosen on safety and efficacy regardless of its natural or synthetic makeup. Some companies overstate the merits of natural ingredients vis-à-vis synthetic ingredients to protect the reputation of the industry. Mintel (2010) found that a third of British women favoured the alternative natural route to improving their appearance, including turning to organics and avoiding chemicals in ingredients and beauty products. Consumers are confused since the concept of 'natural' and 'organic' varies and is inconsistent.

Several studies claim that there has also been a progressive increase in the environmental consciousness of customers, and the concern regarding the environment has moved from a fringe to a mainstream issue (Kalafatis et al. 1999). Ethical consumers have emerged and their major concerns are buying products that are not harmful to the environment and society. They emphasise nutritional value, health, and the quality of food (Wier and Calverley 2002). Their attitudes affect their response to related products and situations (Schiffman and Kanuk 2007; Peter and Olson 2008; Rice 1995). Attitudes can be persistent but are sometimes affected by particular circumstances and vary from situation to situation. Attitude formation includes emotional and social influences such as personal experience, social network, and marketing techniques (Kaplan et al. 2011; Schiffman and Kanuk 2007).

A lot of research has been conducted in the UK regarding buying cosmetics, but very limited studies have explored the formation of consumer attitudes toward green cosmetics. Accordingly, this study determines consumer attitudes toward green cosmetics in the UK market. To this end, the research addresses the following questions: (1) How do British female consumers define green cosmetics? (2) What are the consumer attitudes toward green cosmetic products and the value of natural ingredients? (3) What are the key factors influencing current attitudes and the formation process?

\section{Review of Relevant Work}

\subsection{Definition of Green Cosmetics}

Green cosmetics is defined as being a multifaceted construct for the preservation of the environment, minimisation of pollution, responsible use of non-renewable resources, and animal welfare and species preservation (McEachern and Mcclean 2002). Green or environmentally-friendly products are broadly defined as products that will not pollute the earth or deplete natural resources and can be recycled or conserved (Shamdasani et al. 1993). A study indicated that green cosmetics were natural cosmetics containing botanicals and fruit-based formulae (Csorba and Boglea 2011). Over time, the context has broadened as products that support sustainability increase. The European Cosmetics Standards Working Group launched the Cosmetics Organic and Natural (COSMOS) Standard (D'Amico 2008). 
For further progress, the COSMOS standard certification was officially launched in February 2011, which is trying to be an internationally recognised standard. The similarities of the above studies emphasise that using green cosmetics is a lifestyle of treating self-care and treating the environment with respect.

\subsection{Factors Influencing the Formation of Attitude}

Although green consumption is a new lifestyle, the literature shows consumers' concerns when buying cosmetics. The Cosmetic Toiletry and Perfumery Association (CTPA 2018) summarised that consumer attitudes toward product attributes including functions, ingredients, packaging, fragrance, and price influenced purchase behaviour. Costello (2011) found that around a quarter of British women placed low importance on the breakdown of the ingredients of their cosmetics, and instead focused on product functions. Ma and Yang (2018) found that Chinese females purchase cosmetic products relying on quality, price, and delivery. Dealing with the cognitive components of attitudes, Dimitrova et al. (2009) indicated that consumers' cognition could be learnt and changed through product marketing. To summarise, consumer attitudes vary from person to person due to internal factors like different psychological and emotional feelings and external factors like family preference and social and cultural status. Given that green cosmetics is a new trend with immature certification standards, consumer attitudes can be influenced through marketing techniques on the basis of honest descriptions of product attributes and attractive promotions.

\section{Research Methods}

This study adopted a qualitative research design as it is better suited to explore in-depth consumer attitudes toward green cosmetics by quantifying the data using statistical analyses (Malhotra 2009).

Furthermore, Krueger (1994) pointed out that attitudes and perceptions relating to concepts or products were developed to some extent by interactions with others. Albrecht et al. (1993) suggested that people influenced each other's opinions, and in the course of the discussion, the opinion of an individual might strengthen or shift. As such, the moderator could discover more about change and the influencing factors.

Kitzinger (1995) defined the focus group as a form of group interview that was conducted by a moderator to generate communications between respondents to collect data. The advantages of focus groups are the active interactions among informants, including comments, shared attitudes, and experiences; more flexible structured questions; and a closer relationship between the moderator and informants. Therefore, focus groups have chemistry and a dynamic that are greater than the sum of the members, and they offer more excitement than other research techniques (Keown 1983). Keown (1983) illustrated three steps in focus group research, including pre-research issues, focus group research issues, and post-research issues. In the research design, the objectives of this research are to understand the definition of green cosmetics in the minds of consumers, what are consumer attitudes toward green cosmetics, and what factors will influence the formation of attitude. The questions related to the research objectives were raised in a semi-structured questioning method to ensure the coherence of discussion while permitting some flexibility to lighten up the atmosphere (Neumark-Sztainer et al. 1999).

\section{Data Collection}

British female consumers became the target respondents of this research because they are traditional users of cosmetic products (Costello 2011). The interview was held at a university discussion room. The environment was comfortable and quiet, refreshments were provided to motivate members, and every participant was expected to be able to make eye contact with the moderator and each other to exchange feelings and attitudes (Buber et al. 2004; Kitzinger 1995). The time duration was around one hour, and the process was videotaped for future data analysis.

Table 1 presents the demographic profile of the research respondents. The group members were segmented based on demographic and socioeconomic factors such as age, occupation, and lifestyle. 
Based on the UK female cosmetics consumer age structure, two groups of respondents were chosen from the 20-35 group, two from the 36-50 group, and one group from those aged 51-65. Each group consisted of six members for a total of 30 respondents.

Table 1. The profile of the focus group respondents.

\begin{tabular}{ccc}
\hline Socio-Demographic Attributes of Interviewees & Number & $\mathbf{\%}$ \\
\hline Age & & \\
\hline $21-35$ & 13 & 43.3 \\
$36-50$ & 11 & 36.7 \\
$51-65$ & 6 & 20 \\
\hline Occupation & & \\
\hline Retail store staff & 4 & 13.3 \\
White collar & 6 & 20 \\
Teacher & 4 & 13.3 \\
Hospital staff & 3 & 10 \\
Student & 11 & 36.7 \\
Housewife Self-employed & 2 & 6.6 \\
\hline Income per year & & \\
\hline Below $£ 15,000$ & 9 & 30 \\
$£ 15,000-20,000$ & 11 & 36.7 \\
$£ 20,000-25,000$ & 9 & 30 \\
Above $£ 30,000$ & 1 & 3.3 \\
\hline
\end{tabular}

The detailed moderator outline would be useful to guide the process of the focus group discussion. The group introduction and semi-structured interview guide were involved in this study. The focus groups began with the moderator's self-introduction and welcoming session. After that, the moderator introduced an overview of green cosmetics and the aims of the research. Every respondent received a short survey to record their personal information. They could enjoy refreshments and become familiar with other members in the group (Flamm and Agrawal 2012). After the introduction, the main part started by asking the definition of green in the minds of consumers, and individual contributions were encouraged before beginning the group discussion. Ethical issues were explained to the respondents.

This study opted for a manual data analysis method because the qualitative software required time and skills to learn and the foundation of data analysis including data familiarisation and categorisation could not be eliminated using computer software. Robson (1993) pointed out that the aim of data analysis was data reduction. The structure of analysis should be systematic and consistent (Krueger and Casey 2000). Researchers should begin by watching the recorded focus group sessions, transcribe the conversations and discussions, and then read notes to remember the nonverbal information for a broad overview of the data. Secondly, they should write memos in the margin of the transcript to identify ideas. Based on this initial reading, a classification system for major topics and issues is developed and material in the transcript related to each topic is identified. Colour-coded brackets or symbols could be used to mark different topics within the text. The coded material may be phrases, sentences, or long exchanges between individual respondents. The only requirement is that the material is relevant to the particular category with which it has been identified. The next move was to categorise the deceptive statements in terms of similarities and differences. Each topic is treated in turn with a brief introduction. The transcribed text is used as supporting material and incorporated within an interpretative analysis. Finally, the researcher could use tables and arrange quotes to form an appropriate context (Miles and Hubermann 1994). 


\section{Findings}

\subsection{Consumer Definitions of Green Cosmetics}

To answer the question "How do British female consumers define and measure the standards of green cosmetics?" The majority of respondents had heard of green cosmetics and had some awareness of the topic. However, their definitions of green cosmetics differed. A few respondents were unsure about the definition and did not understand the real meaning of green.

I'm interested in green cosmetics, what is particular green? (Respondent 1, 32 years, retail store staff)

I have heard of [green cosmetics], but I don't know much about it. (Respondent 15, 55 years, teacher)

Several respondents strongly associated green cosmetics with natural and organic cosmetics, and some respondents were inclined to the environmentally-friendly production of cosmetic products. The remaining respondents agreed and added ethical elements such as no animal testing and Fairtrade.

Green cosmetics are made of natural ingredients, no harmful chemicals. They do not pollute the environment. (Respondent 29, 25 years, student)

I think it's basically the production of the cosmetics, and the packaging that causes as little harm as possible to the environment, recyclable, and is sustainable. (Respondent 25, 36 years, university teacher)

In addition, a number of respondents discussed brands that can be categorised as green cosmetics, among which the Body Shop was mentioned most frequently. Most respondents agreed that it was the closest brand to green cosmetics, and valued their campaigns against animal testing, ethical trade, and environmental protection. However, some cautious respondents discovered that the ingredients of the Body Shop's cosmetic products were not $100 \%$ natural as it contained some harmful chemicals. Therefore, they did not trust the brand. Other green cosmetics brands were specified during the focus groups such as Burts Bees, Origin, Aveda, Elemis, Kiehl's, and Lush. Some local private label products can also be grouped into green cosmetics brands and supported by some respondents because they believed green cosmetics should be small instead of international.

Well, I want to say the Body Shop; there are not loads of packaging and no animal testing. I think the Body Shop is green. (Respondent 9, 60 years, retail store staff)

I bought some face food from a local shop, which is lavender, it did work quite well. (Respondent 20, 48 years, white collar)

However, there existed some cautious opinions about the Body Shop, such as distrust and dissatisfaction of its performance.

I found out the Body Shop tries to make out as a green brand, but there are different labels and different warnings. Some of the make-ups are not so clear. (Respondent 3, 46 years, retail store staff)

\subsection{Consumer Attitudes toward Green Cosmetics}

As for "What are consumer attitudes toward green cosmetics?", although the majority of participants were aware of green cosmetics, levels of interest were generally low among British women, especially in the current depressed UK economic climate. On the whole, the majority of respondents held neutral attitudes toward green cosmetics; they did not buy cosmetics because they are green but checked the benefits, including the performance, quality, price, and promotions. 


\subsection{The Tri-Component Model}

According to the tri-component model, consumer attitudes were analysed in three parts. Each part is a key component of exploring consumer attitudes toward green cosmetics.

\subsection{Affective Components}

Affective components are concerned about emotional feelings. After researching, most respondents said they would like to support green cosmetics emotionally because they are kind to the environment and safe to use. The following quotes advocate green cosmetics:

Green cosmetics are good for the environment and your skin. (Respondent 9, 50 years, retail store staff)

I think it is a reasonable thing to do. You should be good to the environment whenever you can. (Respondent 29, 25 years, student)

However, some respondents had little concern about green cosmetics compared to normal cosmetic brands because they paid most attention to the performance of the product instead of green elements.

If I saw something and it's green cosmetics, it's good, but it doesn't influence me. I'm not going to buy it because it's green. I think green cosmetics don't work very well, compared to more established ones, because they got people, bigger brands like Dior and Chanel, they got quite a lot of money to spend on, to make it very good, to develop it, and make it outstanding. Because green cosmetics I feel, are quite new, which don't have the sort of technology to make it work as well. (Respondent 17, 23 years, student)

\subsection{Cognitive Components}

Cognitive components deal with consumer knowledge of the topic. Some respondents had strong supportive attitudes toward green cosmetics because they had adequate knowledge of green cosmetics and they differed in their measurement standards for differentiating green cosmetics from normal cosmetics.

I read the magazine called Natural, which reported a list of companies, you know good companies, Lush is one of them. I always look at the labels, what's recyclable and I'm very careful about what I buy. (Respondent 9, 50 years, retail store staff)

I want to buy more actually [green cosmetics], I think I understand now, and encourage more people to use if I really understood what green products were. (Respondent 20, 48 years, white collar)

However, the major problem facing the green cosmetics industry was that consumers lacked sufficient knowledge of the standard of green cosmetics. On further analysis, neutral cognitive components also influenced the conative components concerning the likelihood or behavioural tendency.

I don't know much about green cosmetics, I don't know what's in it. If I know, I would like to support it, but now I'm not sure. If there is something in the market with reasonable price, all natural, I will probably go for it. (Respondent 23, 32 years, white collar)

When I searched online, some brands said they were green cosmetic brands, but when you looked at the product, there's no way you could tell whether it's green or not. (Respondent 27, 23 years, student) 


\subsection{Conative Components}

Conative components focus on behavioural tendency. When respondents take action to buy cosmetic products, they considered the price and performance.

I think I should be more conscious about that, to be $100 \%$ honest, I care more about the price and performance. I know I should care more about whether it's green or not, but it's not something that I think about. (Respondent 25, 36 years, university teacher)

If I can support myself, I will try to buy more green cosmetics. But now I can't, so I just care more about the price. (Respondent 27, 23 years, student)

\subsection{Factors Influencing the Formation of Attitudes}

The answers to the question "What are the key factors influencing current attitudes and the formation process?" are summarised in the following three main parts.

\subsection{Knowledge about Green Cosmetics}

Lack of knowledge formed neutral attitudes toward green cosmetics. Most respondents were unclear about the standards of green cosmetics:

I think I just don't know about green cosmetics, I can't really see the benefits. I haven't seen any advertising on television or articles. (Respondent 2, 36 years, white collar)

Not much choice as well, I'm aware of advertises. (Respondent 20, 48 years, businesswoman)

\subsection{Lifestyle and Personal Experience}

Lifestyle had a great influence on forming the respondents' attitudes. Some respondents were very conscious of environmental issues, and they felt responsible for purchasing environmentallyfriendly products.

My greatest concern is animal cruelty; I'm a vegetarian though so that goes together actually. I recycle everything, and I'm very careful about what I buy. (Respondent 9, 50 years, retail store staff)

I get results from natural skin cares, so I support it. (Respondent 7, 22 years, student)

\subsection{Mass Media and Family or Friends' Recommendation}

Nowadays, different marketing strategies and media spread messages efficiently and effectively.

Part of it is because my mom supports it, part of it, I read books about it in college. Influences from people that I know and from books and magazines. (Respondent 29, 25 years, student)

I tried different things, and I usually go for what my friends recommended. (Respondent 22, 64 years, teacher)

The above are the main influences that form the present attitudes of consumers toward green cosmetics, their knowledge, and lifestyle. The social surroundings and media also contributed to the formation of the present attitudes.

\section{Discussion}

\subsection{Consumer Definitions of Green Cosmetics}

The majority of respondents considered that the lack of sufficient knowledge available in publications contributed to their definition of green cosmetics, and they were looking forward to 
more developed green cosmetic brands and industry. Most respondents defined green cosmetics from the following aspects:

- Natural ingredients (16 respondents)

- No harmful chemicals (6 respondents)

- Minimum recyclable packaging (11 respondents)

- No animal testing (3 respondents )

- Organic (6 respondents)

- Fairtrade (3 respondents)

The respondents defined green cosmetics in terms of being safe for consumers and respectful to the environment. Compared with the definition from previous studies, definitions from the consumers shared similarities and covered the same essential aspects. The definition of green cosmetics developed from natural ingredients and extended to the environmental footprint of the product throughout the product's life-cycle (Doyle 2011). On further analysis, consumers' definitions focused on natural ingredients, while some paid more attention to the green packaging and production. Only a few respondents considered both dimensions.

The findings of this research showed that the respondents had a general understanding of green cosmetics and their definitions reflected the limited knowledge they learnt from life experience and mass media. Overall, consumers were conscious of the ingredients and the environmental impacts of their cosmetics. What they considered was not only limited to the actual products and packaging but also included the production process that was seldom disclosed by the manufacturers in the past. The above findings agreed with the report of Green Choices (2012), which emphasised that hundreds and thousands of manufacturers produce and sell cosmetic products which they claim were 'green' because of the favourable consumer demand. In addition, the findings shared similarities with Organicmonitor (2012) which demonstrated that the cosmetics industry was getting greener by considering sustainability during production.

However, few respondents were able to point out the precise standard of the specific percentage of natural ingredients required. Therefore, the findings of this research revealed a gap in knowledge between consumer definitions and the COSMOS standard (D'Amico 2008). The standard specifically covered the ingredient source aspect, product aspect, manufacturing aspect, and environmental impact aspect (Payne 2011). The majority of respondents found it difficult to trace the origin and processing of the ingredients of cosmetics. What they could do was check the labels on the packaging, hoping to find some recognisable certifications to approve the greenness of the cosmetics. Some respondents believed the tree or leaf mark as a symbol of green cosmetics, while most regarded these marks as marketing strategies that were not reliable.

\subsection{Consumer Attitudes toward Green Cosmetics}

\subsubsection{Cognitive Components}

Cognitive components centred on consumer knowledge and beliefs. Previous researches demonstrated that consumers who had more environmental knowledge were more inclined to act positively when supporting green products (Polonsky et al. 2012). Knowledge was considered a key element during the formation process of consumer attitudes (Ajzen and Fishbein 1977). The results of this research also revealed that respondents who held strong supportive attitudes toward green cosmetics had a richer knowledge of green cosmetics, including integrated consumer definitions and exact measurement standards of green cosmetics. A higher motivation for advocating environmental protection and being green consumers would lead to stronger supportive attitudes. Those respondents had some characteristics of green consumers, whom Hailes (2007) argued would integrate environmental protection with their daily purchase. Because of the strong environmental 
consciousness, those green respondents said they would like to acquire more knowledge of green cosmetics from different sources such as magazines and articles as well as the internet.

However, respondents with high green consciousness accounted for a small number of the total respondents. The prevailing feelings of respondents were the lack of sufficient knowledge of green cosmetics. Therefore, awareness of the specific definition and measurement standards of green cosmetics needed to be developed.

\subsubsection{Affective Components}

Affective components emphasised consumer feelings and emotions. Hailes (2007) found that green consumers believed their purchasing behaviours would make a difference to the environment and they were responsible for preserving the environment no matter how little their contribution was. Preserving the environment was a responsibility for every citizen of the world. According to Akehurst et al. (2012), socio-demographic and psychographic influences were vital aspects of determining green consumers. Typical green consumers came from the above average social-economic class and were psychologically concerned about environmental protection.

The results of this research agreed that some respondents considered buying green cosmetics as an important part of responsible buying behaviour because green cosmetics were safe for the users and minimised the damage to the environment. Psychologically, those respondents believed that an individual could only make minimal contributions to protecting the environment, but the little contribution would accumulate to make a better world. Most respondents agreed that purchasing green cosmetics was a part of supporting environmental issues, but different people had different motivations. Some respondents viewed cosmetics without animal testing as a top concern because of their lifestyle as vegetarians and animal lovers. Some respondents paid more attention to natural ingredients and recyclable packaging. Therefore, the research showed that the same supportive attitudes could have different motivations and emotions through effective components analysis.

\subsubsection{Conative Components}

Conative components focus on consumer behaviour tendency. Several respondents associated green cosmetics with expensive brands. From their understanding, all natural ingredients equalled higher cost and price. A number of respondents did not trust the cheaper brands that boasted their products as 'green' cosmetics. They preferred that green cosmetics involved luxury appeal, sustainable and natural production, and environmentally friendly campaigns. Some respondents associated green cosmetics as expensive spa products such as Elemis products. According to Elemis' official website (Elemis 2018), Elemis was committed to understanding the earth's natural resources, because its philosophy emphasised the connection of nature and technology for a greater difference. Since those respondents had supportive attitudes, they said they would like to pay extra for green cosmetics, but they also admitted that the depressed economic climate reduces their enthusiasm for paying extra to some extent. This research confirmed that being green consumers and supporting green cosmetics required sufficient financial support. Some respondents commented that it was very difficult for consumers who lived on daily wages to purchase green cosmetics frequently since most green cosmetics targeted the higher market.

Referring to the results of past research (Kim and Seock 2009), this research appealed to the positive relationship between the level of education and income and environmental consciousness. Respondents who had a higher education and good jobs would have more interest in green cosmetics thanks to their awareness of green cosmetics and financial support. On further analysis, based on the results, the vital factors when choosing cosmetics were similar to those listed by the Cosmetic Toiletry and Perfumery Association (CTPA 2018), which summarised the product attributes that influenced actual purchase included functions, price, ingredients, packaging, and fragrance. The majority of respondents took price and performance as priorities for choosing cosmetics, especially during times 
of economic recession. Therefore, the greenness of the cosmetics did not contribute to the tendency of buying cosmetics.

\subsubsection{Factors Influencing the Formation of Attitudes}

The findings of this research agreed with the findings of Schiffman and Kanuk (2007), who emphasised the sources of influence on attitude formation, which include personal experience, social networks, and marketing techniques. Since there was no special course on green cosmetics, most respondents gained knowledge through personal experience or social networking. Internal and external influences contributed to consumer attitudes toward green cosmetics. Based on the results, the factors influencing the formation of attitudes could be divided into the following categories.

\subsubsection{Personal Experience and Lifestyle}

The finding of this research agreed that one common way of forming attitudes was from past experiences (Argyriou and Melewar 2011). Past experiences provided an unconscious way of learning and forming related attitudes. In this research, the past experiences included the experience of using different cosmetics and the lifestyle that respondents advocated. Personal experience and lifestyle did influence the formation of consumer attitudes. In order to choose the most suitable cosmetics, some respondents did not stop trying different brands and products until they found their favoured brands or products. Once they tried a presumed green cosmetic brand such as the Body Shop and did not find the performance satisfying, they did not have supportive attitudes. Therefore, through personal experience of using cosmetics, those respondents who paid more attention to performance and price did not put green aspects as top priorities.

However, other respondents were concerned with environmental protection and animal cruelty, or they were vegetarians. Their green lifestyles stimulated supportive attitudes toward green cosmetics. These findings align with those of Kim and Seock (2009), which discussed consumers' level of environmental consciousness would affect the formation of attitudes. Because cosmetic products played an important role in female consumers' daily life, respondents who had certain awareness about green cosmetic or chemicals would focus on natural ingredients, while others who were interested in green production would concentrate on recyclable packaging, and ethical respondents would centre on no animal testing and Fairtrade.

\subsubsection{Media and Marketing Techniques}

Marketing communication mix is an effective tool when gaining market share in the competitive market (Kotler and Armstrong 2009). Based on the findings of this research, the majority of respondents formed their attitudes by the influence of media and advertising. Trustworthy sources included relevant articles about green cosmetics in leading fashion magazines, reviews of cosmetic products by consumers and professionals in the cosmetic field, and advertising on television or other channels. The respondents pointed out that there were insufficient sources to acquire knowledge about green cosmetics. As such, they had little understanding of green cosmetics. In addition, some advertising was exaggerated, which aroused respondents' caution and distrust.

The findings revealed that the consumers had a strong demand for honest advertising of green cosmetics, which did not appear in the past research. Some argued that the term green cosmetics are bandied around and used freely by cosmetics companies. Getting green certification demonstrates the reassurance that ingredients and products meet specific standards instead of merely a marketing exercise. Since the green cosmetics industry has a huge potential growth (Mintel 2010), consumers were longing for honest advertising that contained the information about the natural ingredients and green production process rather than the gorgeous effects of cosmetics. Consumers were eager to find the available green cosmetics brands in the UK and they welcomed more famous and certified green cosmetics brands and products. In appealing to consumer demand, marketers should use a creative 
marketing communication mix that emphasizes the purity and natural appeal to popularise green cosmetics in the UK market.

\subsubsection{Social Surrounding}

According to Shavitt (1990), attitudes express values, preferences, and self-perceptions to people around them. Attitudes have a value-expressive function and facilitate interpersonal communication (Argyriou and Melewar 2011). Most respondents acknowledged that they preferred trying the products or brands that their friends or family members recommended, especially those who had expertise in cosmetics or had good skin. Word of mouth is influential and leads to favourable attitudes and willingness to try and purchase. Consumers would like to share the experience of using cosmetic products and brands with other consumers, and word of mouth happens when consumers give advice and /or opinions (Romaniuk 2012).

\section{Conclusions}

Consumers' definitions of green cosmetics generally considered natural ingredients and environmental protection. Buying cosmetics was both a personal and environmental issue. Cosmetics should perform will and treat the environment with respect. From the cognitive component, British females differ when measuring the greenness of cosmetics. A total of 16 respondents defined green cosmetics as cosmetics made of natural ingredients, 11 regarded minimum recyclable packaging as green, no harmful chemicals, and organic cosmetics were mentioned by 6 respondents respectively, and 6 respondents emphasised ethical issues such as Fairtrade and no animal testing.

Although green cosmetics have become a heated discussion topic by the media and cosmetic manufacturers, for UK female consumers, green cosmetics is an emerging market and needs more time to grow. There exists a gap between consumer knowledge and the current market situation of green cosmetics. Therefore, most consumers hold neutral attitudes at present. They demand honest advertising of green cosmetics in the mass media including television, leading magazines, and the internet.

Furthermore, the green cosmetics industry should pay attention to the influences of consumer attitude, including knowledge, lifestyle, and mass media. According to Newman (2006), although growth in natural and organic cosmetics is strong, the challenges cannot be ignored, including accurate definitions and enforcement, sustainability, credibility, and marketing. In coping with the inferior performance of green cosmetics, bigger brands can introduce a new range of products with an established and trustworthy brand. More effective marketing efforts are expected to emphasise the standard of green cosmetics and publish the globally recognised label to identify green cosmetics. Additionally, celebrities with a positive image could be invited to advocate healthy and responsible behaviour of using green cosmetics to create a trend in the UK. Being green needs time and financial support and government support could be effective in developing the green cosmetic industry.

\section{Implications}

The literature supports that product knowledge might be gained through interpreting and integrating information from past usage experience and memory (Peter and Olson 2008). This research narrowed the attitudes research to a rather specific green cosmetics context. Focus group research provides a natural setting for data collection and can obtain data on nonverbal behaviour (Marshall and Rossman 2006). Therefore, different opinions and subtle attitudes were encouraged.

As for the practical implications, this research will benefit the development of the green cosmetic industry in the UK. This research identified several steps for developing the green cosmetics market, including understanding the target consumers and improving upon weaknesses, as well as diagnosis of marketing strategies. Since marketers have been provided clues of understanding consumer attitudes, they will be able to develop green cosmetic products that consumers need, supplemented with attractive marketing strategies such as pricing strategy and promotion, honest advertising, 
and convenient purchase channels. Lutz (1975) found that attitude-change strategies are effective to deal with the present prevailing neutral attitudes. These efforts hopefully contribute to a more promising green cosmetics industry in the UK.

\section{Limitation and Further Study}

The main limitation of the research was the data collection. Some of the respondents would guess the purpose of this research and tried to appeal to other group members. They were reluctant to reveal their true attitudes and followed other group members. Due to the limited time and insufficient training of the moderator, possible misinterpretations might exist. Moreover, cultural differences and misunderstandings might exist during data collection, so more focus groups are needed to maximise the accuracy and integrity of this focus group research.

Future research could adopt a quantitative methodology (via a survey, for example) to assist the finding of this research and represent larger segments of the population. Moreover, there are increasing numbers of male consumers of cosmetic products. As such, we suggest considering male respondents and their attitudes toward green cosmetics, which might form more complete research. Since consumer attitudes might change with the development of a green cosmetic industry, we suggest conducting another research on the same topic in two years to compare with the current research results and analyse the development of consumer knowledge and the stability of current consumer attitudes.

Author Contributions: The authors have contributed equally in the literature review, research design and development, the data analysis, and the writing of the paper. The authors have read and approved the final manuscript.

Funding: This research received no external funding.

Conflicts of Interest: The authors declare no conflict of interest.

\section{References}

Ajzen, Icek, and Martin Fishbein. 1977. Attitude-behaviour relations: A theoretical analysis and review of empirical research. Psychological Bulletin 84: 888-918. [CrossRef]

Akehurst, Gary, Carolina Afonso, and Helena Martins Gonçalves. 2012. Re-examining green purchase behaviour and the green consumer profile: New evidences. Management Decision 50: 972-88. [CrossRef]

Albrecht, Terrance L., Gerianne M. Johnson, and Joseph B. Walther. 1993. Understanding communication processes in focus groups. In Successful Focus Groups: Advancing the State of the Art. Edited by David L. Morgan. Thousand Oaks: SAGE Publications, vol. 156, pp. 51-64.

Argyriou, Evmorfia, and T. C. Melewar. 2011. Consumer attitudes revisited: A review of attitude theory in marketing research. International Journal of Management Reviews 13: 431-51. [CrossRef]

Bird, Katie. 2009. Is Natural Really Better in the World of Cosmetics? Cosmetics Desigh-Europe. Available online: http://www.cosmeticsdesign-europe.com/Formulation-Science/Is-natural-really-better-in-theworld-of-cosmetics (accessed on 4 May 2018).

Buber, Renate, Johannes Gadner, and Lyn Richards. 2004. Applying Qualitative Methods to Marketing Management Research. New York: Palgrave Macmillian. ISBN 978-1-4039-1660-0.

Costello, Brid. 2011. Facial Skincare Executive Summary-UK-June 2011 Mintel. Available online: http:// academic.mintel.com/sinatra / oxygen_academic/search_results/show\&/display /id=545513 (accessed on 10 November 2018).

Csorba, Luiela Magdalena, and Vanina Adoriana Boglea. 2011. Sustainable cosmetics: A major instrument in protecting the consumer's interest. Regional and Business Studies 3: 167-76.

CTPA. 2018. Supplying Cosmetic Products on the UK market? A CTPA Guide to What You Need to Know. Available online: http:/ / www.ctpa.org.uk / (accessed on 15 November 2018).

D'Amico, E. 2008. European group drafts natural and organic cosmetics standards. Chemical Week 170: 31.

Dimitrova, Vesselina, Mariana Kaneva, and Teodoro Gallucci. 2009. Customer knowledge management in the natural cosmetics industry. Industrial Management \& Data Systems 170: 1155-65.

Doyle, L. 2011. A deeper shade of green. Global Cosmetic Industry 179: 48-50. 
Elemis. 2018. Elemis Philosophy Elemis Official Website. Available online: http:/ / www.elemis.com/OurStory / elemisphilosophy.aspx (accessed on 5 November 2018).

Flamm, Bradley J., and Asha Weinstein Agrawal. 2012. Constraints to green vehicle ownership: A focus group study. Transportation Research Part D: Transport and Environment 17: 108-15. [CrossRef]

Green Choices. 2012. Toiletries \& Cosmetics Green Choices. Available online: http:/ /www.greenchoices.org/ green-living/toiletries-cosmetics (accessed on 1 July 2018).

Hailes, Julia. 2007. The New Green Consumer Guide. London: Simon and Schuster.

Kalafatis, Stavros, Michael Pollard, Robert East, and Markos H. Tsogas. 1999. Green Marketing and Ajzen's Theory of Planned Behaviour: A Cross-market Examination. Journal of Consumer Marketing 16: 441-60. [CrossRef]

Kaplan, Avi, Idit Katz, and Hanoch Flum. 2011. Motivation theory in educational practice: Knowledge claims, challenges, and future directions. In Educational Psychology Handbook. Edited by Karen R. Harris, Steve Graham and Tim Urdan. Washington: American Psychological Association, vol. 2.

Keown, Charles. 1983. Focus groups research: Tool for the retailer. Journal of Small Business Management 21: 59-65.

Kim, Soyoung, and Yoo-Kyoung Seock. 2009. Impacts of health and environmental consciousness on young female consumers attitude toward and purchase of natural beauty products. International Journal of Consumer Studies 33: 627-38. [CrossRef]

Kitzinger, Jenny. 1995. Qualitative Research: Introducing focus groups. The British Medical Journal 311: $299-302$. [CrossRef] [PubMed]

Kotler, Philip, and Gary Armstrong. 2009. Principles of Marketing, 11th ed. New York: Pearson Education.

Krueger, Richard A. 1994. Focus Group: A Practical Guide for Applied Research, 2nd ed. London: Sage.

Krueger, Richard A., and Mary Anne Casey. 2000. Focus Groups: A Pratical Guide for Applied Research, 3rd ed. Thousand Oaks: Sage Publications.

Lutz, Richard J. 1975. Changing brand attitudes through modification of cognitive structure. Journal of Consumer Research 19: 49-59. [CrossRef]

Ma, Yaxin, and Shaohua Yang. 2018. An empirical study of female e-shopper's satisfaction with cosmetic products in China. International Journal of Business and Management 13: 211. [CrossRef]

Malhotra, N. K. 2009. Marketing Research: An Applied Orientation, 6th ed. New York: Pearson.

Marshall, Catherine, and Gretchen B. Rossman. 2006. Designing Qualitative Research, 4th ed.Thousand Oaks: Sage Publications.

Mason, Sara. 2012. Ingredients Innovation: Inspired by Nature. Global Cosmetic Industry 180: 44-47.

McEachern, Morven G., and Paulin Mcclean. 2002. Organic purchasing motivations and attitudes: Are they ethical? International Journal of Consumer Studies 26: 85-92. [CrossRef]

Miles, Matthew B., and A. Michael Hubermann. 1994. Qualitative Data Analysis: An Expanded Sourcebook, 2 nd ed. London: Sage Publications.

Mintel. 2009. Consumer Attitudes toward Beauty Product Ingredients-UK-May 2009' Mintel Oxegen. Available online: http:/ / academic.mintel.com/display/456599/ (accessed on 28 July 2018).

Mintel. 2010. Natural and Organic Beauty-UK-February 2010' Mintel Oxegen. Available online: http: / academic. mintel.com/sinatra/oxygen_academic/search_results/show\&/display/id=479857 (accessed on 13 July 2018).

Minte. 2018. Global Beauty Trends 2018. Available online: http:/ /www.mintel.com/beauty-trends/ (accessed on 12 November 2018).

Neumark-Sztainer, Dianne, Mary Story, Cheryl Perry, and Mary Anne Casey. 1999. Factors influencing food choices of adolescents: Findings from focus-group discussions with adolescents. Journal of the American Dietetic Association 99: 929-37. [CrossRef]

Newman, K. A. 2006. Sustaining natural growth (Cover Story). Global Cosmetic Industry 174: 32-36.

Organicmonitor. 2010. About the Summit Organicmonitor. Available online: http://www. sustainablecosmeticssummit.com/Europe/aboutthesummit.htm (accessed on 1 June 2017).

Organicmonitor. 2012. The Greening of the Cosmetic \& Personal Care Industry Gathers Pace' Organicmonitor. Available online: http:/ / www.organicmonitor.com/r1104.htm (accessed on 1 June 2018).

Packaging Digest. 2010. Cosmetics slow to embrace sustainable packaging. Packaging Digest 47: 22.

Payne, C. 2011. COSMOS-Standard for Natural \& Organic Cosmetic Certification is Launched Natural Cosmetic News. Available online: http://www.naturalcosmeticnews.com/organic-label/cosmos-standard-fornatural-organic-cosmetic-certification-is-launched/ (accessed on 25 April 2012).

Peter, J. Paul, and Jerry C. Olson. 2008. Consumer Behavior and Marketing Strategy, 8th ed. New York: McGraw-Hill. 
Polonsky, Michael Jay, Andrea Vocino, Stacy Landreth Grau, Romana Garma, and Ahmed Shahriar Ferdous. 2012. The impact of general and carbon-related environmental knowledge on attitudes and behaviour of US consumers. Journal of Marketing Management 28: 238-63. [CrossRef]

Rice, Chris. 1995. Understanding Customers, 2nd ed. Oxford: Butterworth-Heinemann.

Robson, Colin. 1993. The Real-World Research-A Research of Social Scientists and Practitioner-Researchers. Oxford: Blackwell Publications.

Romaniuk, Jenni. 2012. The various words of mouth moving beyond the road-to-damascus conversion. Journal of Advertising Research 52: 12-14. [CrossRef]

Schiffman, Leon G., and Leslie Lazar Kanuk. 2007. Consumer Behaviour, 9th ed. Upper Saddle River: Prentice Hall.

Shamdasani, Prem, Gloria Ong Chon-Lin, and Daleen Richmond. 1993. Exploring green consumers in an oriental culture: Role of personal and marketing mix. Advances in Consumer Research 20: 488-93.

Shavitt, Sharon. 1990. The role of attitude objects in attitude functions. Journal of Experimental Social Psychology 26: 124-48. [CrossRef]

Stone, George, James H. Barnes, and Cameron Montgomery. 1995. Ecoscale: A scale for the measurement of environmentally responsible consumers. Psychology and Marketing 12: 595-612. [CrossRef]

Wier, Mette, and Carmen Calverley. 2002. Market perspectives for organic foods in Europe. British Food Journal 104: 45-62. [CrossRef]

Yeomans, Michelle. 2012. Natural \& Organic Show Sees Growth in Cosmetic Despite Economic Challenges Cosmetics Design-Europe. Available online: http:/ / www.cosmeticsdesign-europe.com/Market-Trends / Natural-Organic-show-sees-growth-in-cosmetics-despite-economic-challenges?utm_source=copyright\& utm_medium=OnSite\&utm_campaign=copyright (accessed on 26 July 2013).

(C) 2018 by the authors. Licensee MDPI, Basel, Switzerland. This article is an open access article distributed under the terms and conditions of the Creative Commons Attribution (CC BY) license (http:/ / creativecommons.org/licenses/by/4.0/). 